\title{
A Component of the Puzzle, When Attempting to Understand Antipsychotics: A Theoretical Study of Chemical Reactivity Indexes
}

\author{
Ana Martínez ${ }^{1 *}$ and Rubicelia Vargas ${ }^{2}$ \\ ${ }^{1}$ Instituto de Investigaciones en Materiales, Universidad Nacional Autónoma de México, Circuito Exterior S. N., Ciudad Universitaria, CP 04510, \\ CDMX, México \\ ${ }^{2}$ Departamento de Química, División de Ciencias Básicas e Ingeniería, Universidad Autónoma Metropolitana-Iztapalapa, San Rafael Atlixco 186, Col. \\ Vicentina, Iztapalapa. AP Postal 55-534, CP 09340, CDMX, México
}

${ }^{*}$ Correspondence to: Ana Martínez, Instituto de Investigaciones en Materiales, UNAM Circuito Exterior s/n, Ciudad Universitaria, P.O. Box 70-360, Coyoacán, 04510, Ciudad de México; Tel: 5255 56224596; Email: martina@unam.mx

Received: November 11, 2018; Accepted: November 17, 2018; Published: November 17, 2018;

\begin{abstract}
Schizophrenia is a human condition that has attracted the attention of researchers. There is no cure for schizophrenia but several treatments can help control symptoms (hallucinations and delusions). Dopamine D2 receptor antagonists are mainly effective for the treatment of psychotic symptoms, hence the name "antipsychotic". This study principally aims to conduct a quantum chemical analysis of one family of antipsychotics. New physical insights have attempted to explain the pharmacological action mechanism of these drugs. Two questions for which we found a possible answer are: why the Defined Daily Dose (DDD) of these drugs varies and what do we have to consider when attempting to improve the effectiveness of medications? Although DDD is a complex concept related with pharmacokinetics, in this investigation we report some insights concerning the chemical reactivity that could be useful. These drugs are antagonists of dopamine. This means that they occupy the same receptor, but refrain from activating it. We found that the more they differ from those found in dopamine, the lower DDD is required. Chemical reactivity indexes of antipsychotics should to be different from those of dopamine. These ideas represent an aspect of the complex puzzle that contributes to define the pharmacological action of antipsychotics.
\end{abstract}

Keywords: Antioxidant, DAM, Density Functional Theory, Lagartil ${ }^{\circledast}$, Schizophrenia

\section{Introduction}

Psychosis comprises a group of symptoms. An episode of psychosis is recognized when people "break" with reality. One type of psychosis is known as schizophrenia. Schizophrenia is a chronic brain disorder, affecting one percent of the global population [1-12]. The symptoms of this disorder include delusions and hallucinations. When these symptoms are treated, most people with schizophrenia improve their social function and can be re-integrated into their family and workplace. Specific treatment can help people with schizophrenia to become highly productive and develop social skills, which allow them to become adapted to their social environment.

Schizophrenia is a human condition that has attracted the attention of researchers. The etiology is complex and unknown. Moreover, there is no cure for schizophrenia, although several remedies can control symptoms [5-8]. Until the 1950s, a number of medicines manifesting restricted clinical effectiveness were used to treat the symptoms of psychosis. Electroconvulsive therapy or treatments containing a number of unspecified pharmacological agents, such as opium, morphine and cocaine, were administered with limited success [9]. The most important advance occurred in 1952 with the serendipitous observations by Laborit, which described the effect of chlorpromazine on patients suffering an episode of psychosis $[10,11]$. This drug has mainly proved effective for the treatment of psychotic symptoms (hallucinations and delusions), hence the name "antipsychotic". Chlorpromazine is considered as the prime antipsychotic drug and works as a dopamine D2 receptor antagonist. Since the initial discovery of chlorpromazine, many investigations have focused on the development of new and safer treatments [12-19].

The introduction of chlorpromazine represented the first selective and effective approach to the treatment of schizophrenia, initiating the psychopharmacological era [10-19]. Ever since this finding, many investigations were undertaken, focusing on the synthesis of numerous antipsychotic drugs [1]. Those that function as a dopamine D2 receptor antagonist are considered as the first generation of antipsychotics and include different chemical compounds, such as derivatives of phenothiazine. They can be classified according to their clinical potency that correlates with dopamine D2 receptor affinity [19].

Phenothiazine is an organic compound, the molecular formula for which is presented in Figure 1. Derivatives of phenothiazine are substances that present antiemetic, antipsychotic, antihistaminic and anticholinergic activities [20-23]. The phenothiazine group of drugs is used when patients do not respond to other antipsychotics and they were one of the most widely prescribed psychotropic drugs in 
the world [22]. Information relating to the toxic and beneficial effects of these drugs has been discussed [21] and the value of gaining a comprehensive knowledge about their mechanism of action in order to ensure appropriate clinical application of phenothiazines [22] is recognized. Other reports suggest that the level of substitutions [23] is a factor defining the efficaciousness of this group of drugs and it has been proposed that the involvement of different molecular orbitals is related to the expression of distinct biological activities. Previous results reported that pharmacological action is influenced by the nature of substitutions, which modify receptor specificity $[24,25]$.

Although many studies have investigated the pharmacological action of these drugs, the exact antagonistic mechanism of the dopamine D2-receptor is still unknown. In this investigation, we aim to undertake a quantum chemical analysis of antipsychotics derived from phenothiazine. Principally, our strategy is to apply simple quantum chemical models in order to reveal the complex operation of these molecules. We applied chemical reactivity indexes and electron transfer models, previously used to successfully explain a number of reactions [26-29], to provide new explanations for the pharmacological action mechanism of these drugs. We found a possible answer to the following questions: why the Defined Daily Dose (DDD) of these antipsychotics varies, and which future strategies appear competent for improving the effectiveness of medications? Any possible solutions, not only relate to geometry, but also to electron transfer ability. Results from this research indicate that different doses of medication, reported previously, relate to electron donoracceptor capacity. These drugs are antagonists of dopamine, because they occupy the same receptor without activating it. This leads us to the conclusion that an effective antagonist of dopamine, in the form of antipsychotic drugs, must have different electron donor acceptor properties and moreover, the more they vary from dopamine, the more efficient they will be. The outcomes reported here help to elucidate the complicated action mechanism manifested by drugs used in the treatment of schizophrenia (Figure 1).<smiles></smiles>

Figure 1. Molecular formula of different phenothiazine derivatives. $\mathrm{R} 1$ is equal to $\mathrm{H}$ for phenothiazine.

\section{Computational Details}

Gaussian09 was used for all electronic calculations [30]. Geometry optimizations without symmetry constraints were implemented at M06/6-311+G(2d, p) level of theory [31-35], while applying the continuum solvation model density (SMD) with water, in order to mimic a polar environment [36]. Harmonic analyses were calculated to verify local minima (zero imaginary frequencies). Initial geometries were obtained from PubChem database, but different conformers of each molecule were also optimized. The ground states are those that come from PubChem [37].
In order to analyze electron-donor acceptor properties, vertical ionization energy $(I)$ and vertical electron affinity $(A)$ were obtained from single point calculations of the corresponding cationic and anionic molecules, using the optimized structure of the neutrals. The same level of theory was used for all computations. Electrodonating $\left(\omega^{-}\right)$and electroaccepting $\left(\omega^{+}\right)$power was previously reported by Gázquez et al $[38,39]$. These authors defined the propensity to donate charge or $\omega^{-}$as follows:

$$
\omega^{-}=\frac{(3 I+A)^{2}}{16(I-A)}
$$

Whereas the propensity to accept charge or $\omega^{+}$is defined as

$$
\omega^{+}=\frac{(I+3 A)^{2}}{16(I-A)}
$$

Lower values of $\omega^{-}$imply greater capacity for donating charge. Higher values of $\omega^{+}$imply greater capacity for accepting charge. In contrast to $I$ and $A, \omega^{-}$and $\omega+$ refer to fractional charge transfer. This definition is based on a simple charge transfer model expressed in terms of chemical potential and hardness. The Donor-Acceptor Map defined previously $[40,41]$ is a useful graphic tool. We have plotted $\omega^{-}$and $\omega^{+}$(Figure 2) on this map, enabling us to classify substances as either electron donors or acceptors. Electrons are transferred from good donor systems (down to the left of the map) to good electron acceptor systems (up to the right of the map) (Figure 2).

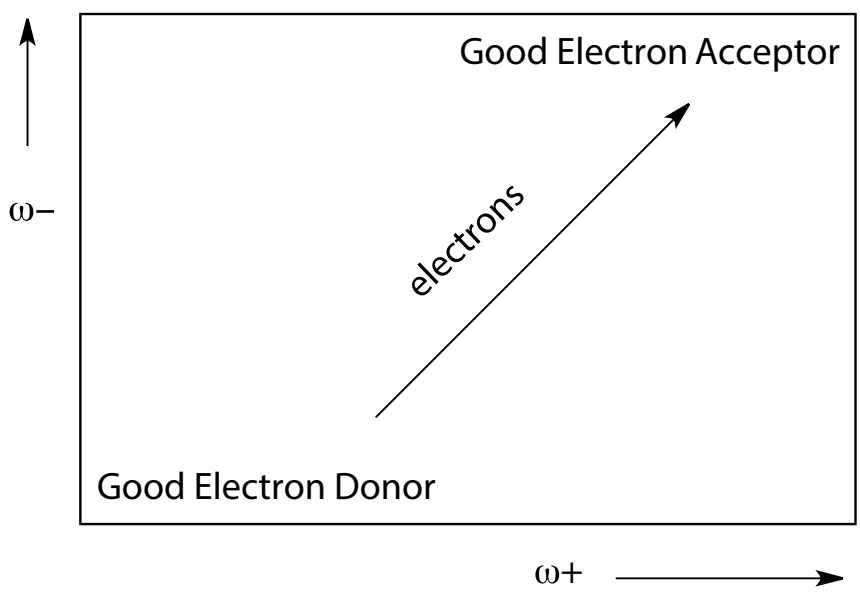

Figure 2. Donor-Acceptor Map (DAM).

\section{Results and Discussion}

Figure 3 presents a schematic representation of the compounds that are analyzed in this investigation. There are phenothiazinederivatives with different substituents. Promethazine is not an antipsychotic drug and is included for comparison purposes. Defined Daily Doses (DDDs) are also cited, as this parameter relates to the efficacy and potency of the compounds. Certain reports correlate the action at the receptor levels of these drugs with required doses. Those that require smaller doses are more effective and usually present fewer side effects [42-44]. In this investigation, we correlate DDD with different structural parameters and distinct electronic properties. 


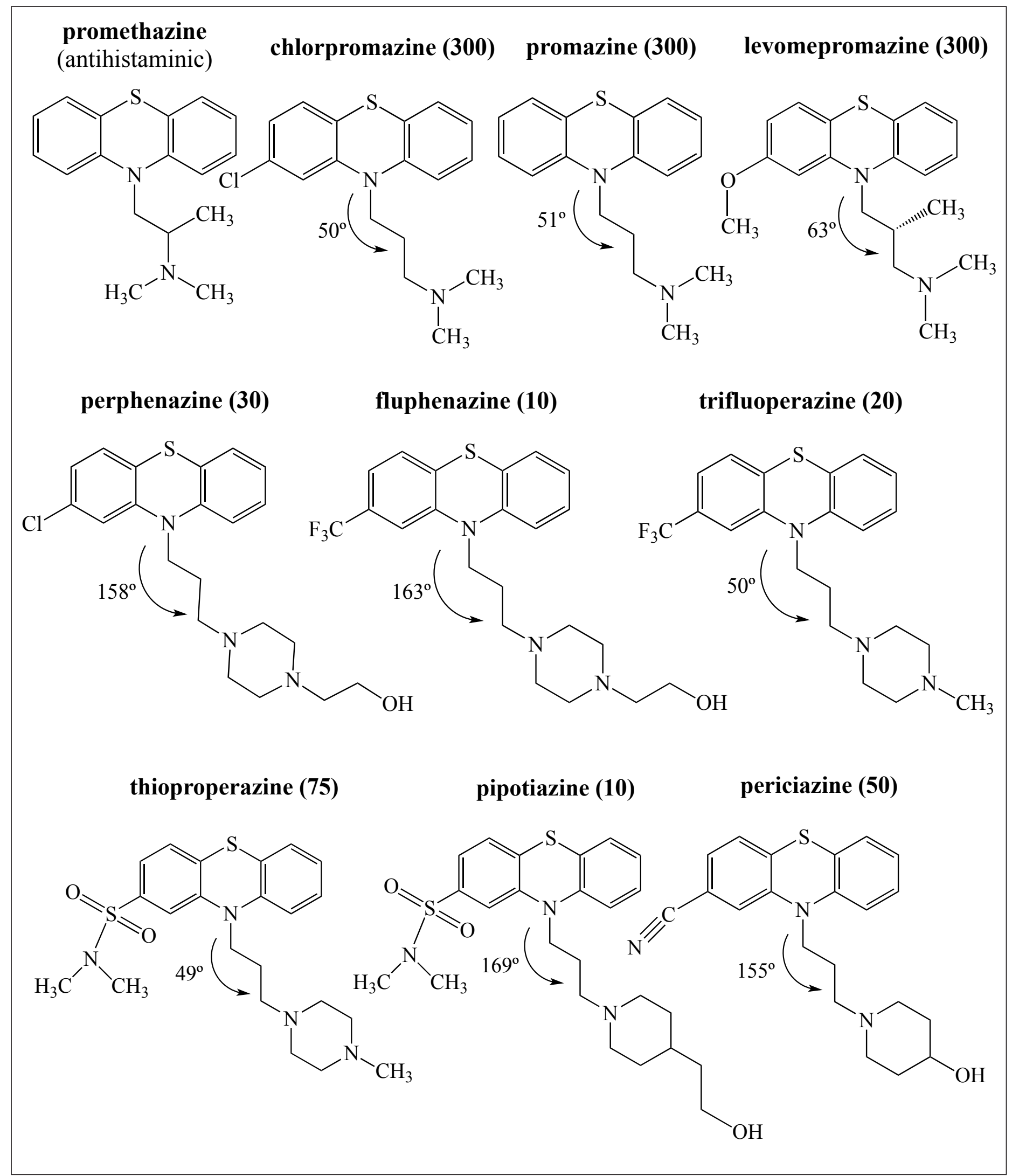

Figure 3. Schematic representation of the molecular formula of phenothiazine derivatives investigated in this work. Defined Daily Doses (DDDs) are included (as mg/day) as is the NCCC dihedral angles (in degrees) for the optimized structures obtained in this investigation. 
All antipsychotic drugs in Figure 3 are molecules that include $\mathrm{R} 1$ as their substituent with the following chain; $-\mathrm{CH}_{2}-\mathrm{CH}_{2}-\mathrm{CH}_{2}-\mathrm{N}-$. Promethazine contains a substituent that is -C-C-N-, and it is not an antipsychotic drug. The first three antipsychotic molecules presented in Figure 3 have similar structures and the same DDD. Apparently, the presence of $-\mathrm{Cl},-\mathrm{O}-\mathrm{CH}_{3}$, or $-\mathrm{CH}_{3}$ groups does not modify their efficacy. Molecules with lower DDDs are those compounds with a six-member ring instead of methyl groups in R1. In order to increase their efficacy and therefore decrease DDD, it is important to replace the methyl groups with a six-member ring. Comparing the NCCC dihedral angles, also depicted in Figure 3, there are two types of compounds: those for which NCCC $<100^{\circ}$ and those for which NCCC $>150^{\circ}$. DDD is less for compounds with larger dihedral angles than for those antipsychotic molecules with smaller dihedral angles; the only exception is trifluoperazine. These observations show that as expected, geometrical structure and chain composition relate to DDD. All these molecules bind to D2 receptors in the brain and act as dopamine D2 receptor antagonists. Therefore geometry is important.

Even when most R2 in the antipsychotic molecules represent electron-withdrawing substituents, different effects are evident. Comparing the molecular formula of perphenazine with that of fluphenazine, the difference is the $\mathrm{R} 2$ substituent $\left(\mathrm{Cl}\right.$ and $\mathrm{CF}_{3}$, respectively) and the DDD of fluphenazine is one third that of perphenazine. When we compare trifluoperazine and thioproperazine, results are the same. Molecular structures are similar with different $\mathrm{R} 2$ substituents. Trifluoperazine contains $\mathrm{CF}_{3}$ substituent, whereas thioproperazine does not; DDD of trifluoperazine is also almost one third of thioproperazine. It appears that the presence of $\mathrm{CF}_{3}$ in the molecule decreases the required doses, i.e. efficacy increases (Figure 3).

Likewise, comparisons indicate that thioproperazine and pipotiazine have the same $\mathrm{R} 2$ but different $\mathrm{R} 1$ (with $-\mathrm{NCH}_{3}$ and $-\mathrm{CH}$ $\mathrm{CH}_{2}-\mathrm{CH}_{2}-\mathrm{OH}$, respectively). The last of these is more effective than the first. We can assume that the presence of $\mathrm{OH}$ in the chain increases efficiency. The last compound in Figure 3 has $\mathrm{CN}$ as $\mathrm{R} 2$ and $\mathrm{OH}$ in R1. The required dose is not one of the smallest (50). It seems that potency is not associated with the presence of $\mathrm{CN}$. With all these evaluations, it is apparent that chemical structure does not completely explain the variation in required doses.

An association can be found between DDD and electron transfer capacity using $\omega+$ and $\omega-$. For this purpose, figure 4 reports the DAM of the antipsychotic drugs. Phenothiazine and dopamine are also included for comparison. All compounds that need greater DDD are located down to the left (good electron donors), whereas compounds that required lower DDD are situated up to the left (good electron acceptors). The antipsychotics promazine and levopromazine represent the best electron donors, followed by chlorpromazine. Periciazine, pipotiazine and thioproperazine are the best electron acceptors. Compounds containing DDD equal to $300 \mathrm{mg} /$ day constitute better electron donors than those with DDD of less than $100 \mathrm{mg} /$ day. Moreover, antipsychotics that require a dose of less than $100 \mathrm{mg} /$ day are better electron acceptors $\left(\omega^{+}>1.5\right)$. The only exception is perphenazine, as $\omega^{+}$is less than 1.5 but its DDD is $30 \mathrm{mg} /$ day (Figure 4).

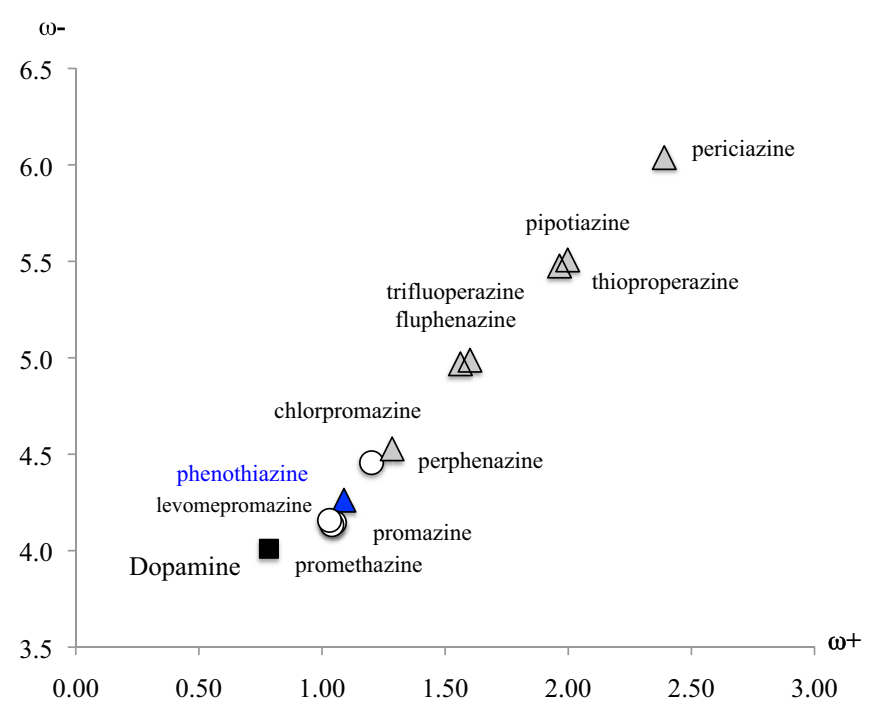

Figure 4. DAM of the antipsychotic drugs studied in this investigation. Other compounds are included for comparison.

These antipsychotics are dopamine D2 receptor antagonists. Therefore, it is interesting to compare these with dopamine's electron donor acceptor capacity. The optimized structure of dopamine is reported in Figure 5. The $\omega$ - and $\omega+$ values are smaller for dopamine than for other compounds, meaning that it represents the best electron donor and also the worst electron acceptor. More efficient compounds (lower DDD) are those that differ most from dopamine. Apparently, it is not necessary to manifest an electron donor acceptor capacity similar to dopamine in order to be an effective antipsychotic. On the contrary, these differences appear to be necessary. One way of understanding these results is to bear in mind that these drugs are antagonists of dopamine. They occupy the same receptor but do not activate it. This activation may partly relate to the transfer of electrons. Concurring with this idea, if the dopamine D2 receptor is blocked without activating it, the capacity to transfer electrons should be different. This explains why those antipsychotics that require lower DDD are those that differ most from dopamine (Figure 5).

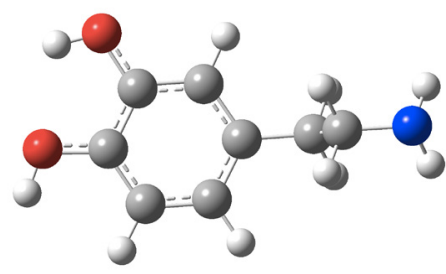

Figure 5. Optimized structure of dopamine.

Other chemical indexes are valuable in this analysis, as they provide further physical insights that will enable us to answer the principal questions. These include first excitation energy and molecular hardness $(\eta)$. The gap of the frontier orbitals (HOMOLUMO gap) in the Kohn-Sham context is an approximation to the first excitation energy $[45,46]$. An approximation of $\eta$ is obtained with the following equation $[38,39,47]$.

$$
\eta=I-A(3)
$$


The absolute values for eigenvalues of the Highest Occupied Molecular Orbitals (HOMO) and the Lowest Unoccupied Molecular Orbitals (LUMO) are reported in Figure 6. The HOMO-LUMO gap is also included. HOMO eigenvalues are similar (5.51-5.68 eV) but LUMO values show more variation $(0.68-1.54 \mathrm{eV})$. The largest HOMO-LUMO gap is for dopamine $(5.94 \mathrm{eV})$ and the smallest for periziacine $(4.14 \mathrm{eV})$. There seems to be a correlation between HOMO-LUMO gap and efficacy, as the smallest values correspond to antipsychotics drugs that require lower doses. According to Figure 6, lower excitation energies correlate with lower DDDs. This means that they are more efficient as antipsychotic drugs. As antagonists, these molecules also differ from dopamine in terms of this property. The excitation energy may also relate to the activation of the $\mathrm{D} 2$ receptor. In order to be an antagonist, excitation energy should be less than that of dopamine. Accordingly, the antagonist will not activate the receptor (Figure 6).

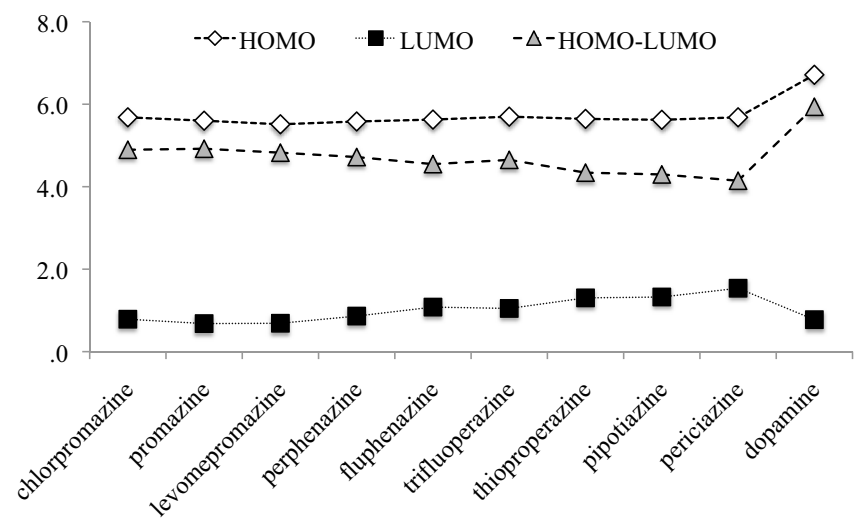

Figure 6. Eigenvalues (absolute values in eV) of HOMO and LUMO of the molecules studied here. HOMO-LUMO gap is also reported.

Figure 7 presents the results for $\eta$. In conformity with ideas from Parr et al [47], systems are more reactive when $\eta$ is small. In our systems, lower values of $\eta$ are associated with lower DDD values and therefore, greater efficiency. For example, the $\eta$ of periciazine is $0.8 \mathrm{eV}$ smaller than the corresponding value for chlorpromazine, and for periciazine it is 1.8 $\mathrm{eV}$ smaller than the corresponding value for dopamine. Compounds that require lower DDD manifest the greatest variation, when compared to dopamine. To be an effective antagonist, $\eta$ has to be smaller than the corresponding value for dopamine. This could be related with the receptor binding affinity of antipsychotics. Investigations concerning the receptor and the interactions with these drugs are in process. However, these results could explain why there is a need for varying DDD and they also provide inspiration concerning possible strategies to improve the effectiveness of medications (Figure 7).

In summary, electron donor acceptor capacity, excitation energies and molecular hardness are global chemical indexes that could help us to explain different DDD values. In order to investigate local properties, we analyzed frontier molecular orbitals and Model Electrostatic Potential (MEP). It was previously reported that different molecular orbitals might relate to distinct biological activities. Figure 8 reports HOMO and LUMO of the compounds under study. In all cases, HOMOs and LUMOs are $\pi$ bonding orbitals located in the phenothiazine fragment. The exceptions are for pipotiazine and periciazine, as LUMOs are antibonding $\pi$ orbitals. No system has the participation of halogens, sulfur or $\mathrm{CN}$ in the frontier molecular orbitals. Because there are no differences, it is not possible to use molecular orbitals in order to explain dissimilarities in the efficacy and potency of these drugs. According to these results, the involvement of different molecular orbitals is not related to the expression of distinct activities (Figure 8).

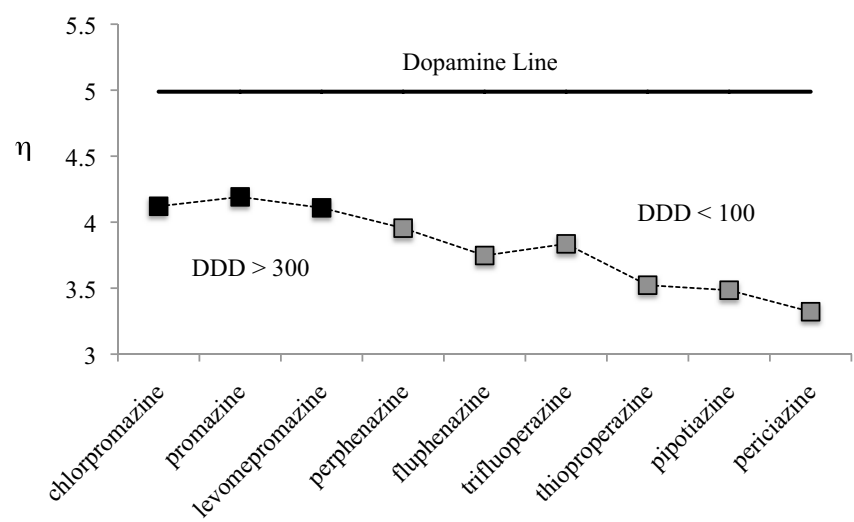

Figure 7. Molecular hardness $(\eta=I-A)$ of antipsychotics. Dopamine value is included for comparison. Values in $\mathrm{eV}$

Figure 9 reports MEP for all compounds under study. Red zones are negative regions, whereas blue sections are positive. The biggest difference is the presence of negative sections in those compounds that require lower DDD. Dopamine does not present these red zones, possibly indicating that local properties need to differ from those of dopamine, in order to increase efficiency (Figure 9).

\section{Conclusions}

All results reported in this investigation focus on the properties of one family of antipsychotic drugs. It is apparent that the geometry and nature of substituents are important for increasing efficiency. This is a logical finding, as all these molecules bind to D2 receptors in the brain, acting as dopamine D2 receptor antagonists. Structure should be an important factor, in terms of occupying the receptor site. Nevertheless, geometrical comparisons are not sufficient to explain differences in DDD as no differences were found. Neither is possible to use frontier molecular orbitals to explain dissimilarities in the efficacy and potency of these drugs.

Electronic properties allow us to classify the best antipsychotic drugs as good electron acceptors and also as molecules that have negative sections in the MEP. Lesser hardness and lower excitation energies are also associated with lower DDD values. Dopamine is the best electron donor and the worse electron acceptor, whereas one of the most efficient antipsychotic drugs (pipotiazine) represents one of the best electron acceptors and one of the worst electron donors. Concerning molecular hardness, dopamine presents the greatest hardness, whereas the best antipsychotics present the least. Similar results are observed when comparing excitation energies. In summary, compounds with greater efficiency (lower DDD) constitute those that differ most from dopamine. It appears that it is not necessary to have 
similar capacities to those manifested by dopamine. Contrarily, given that these antipsychotics act as antagonists that occupy the receptor but do not activate it, their properties should vary from those of dopamine. Although the DDD concept is complicated and it is related with the pharmacokinetics, these results allow us to give some insights concerning the activity of these drugs. The results presented here represent a component in the complex puzzle that defines the action mechanism of antipsychotics.

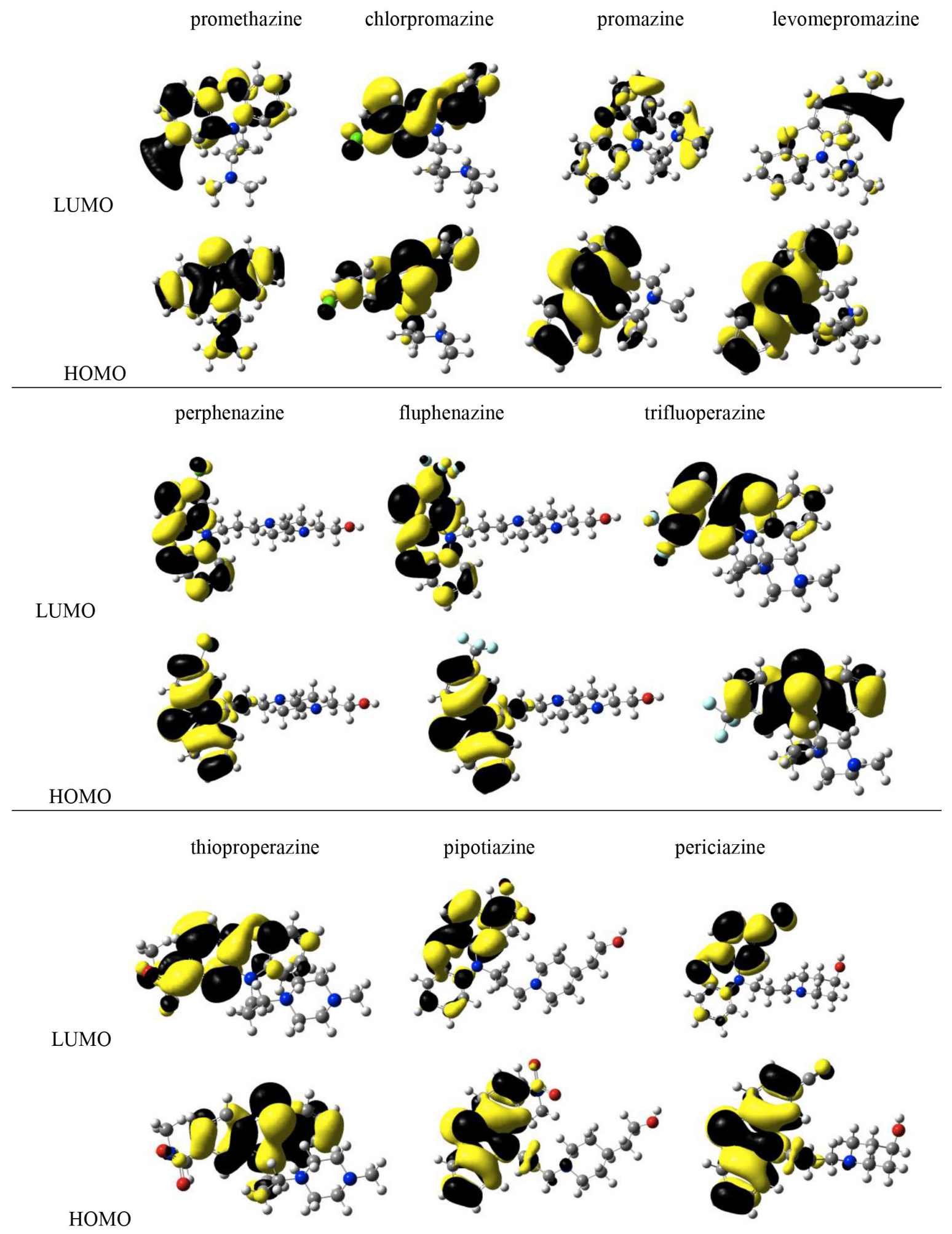

Figure 8. Frontier molecular orbitals of the systems being studied. 


\section{Dopamine}

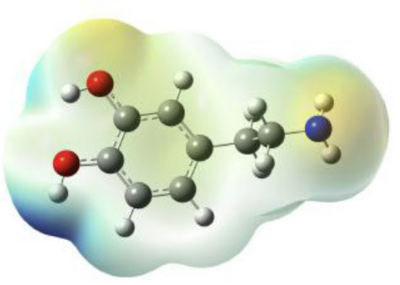

\section{Promethazine Chlorpromazine Promazine Levomepromazine}

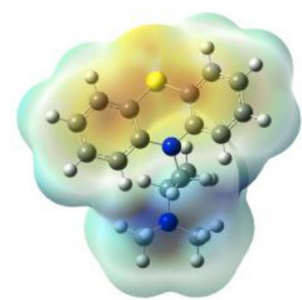

Perphenazine

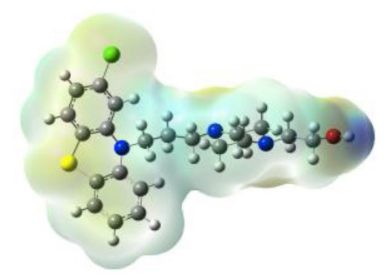

Thioproperazine

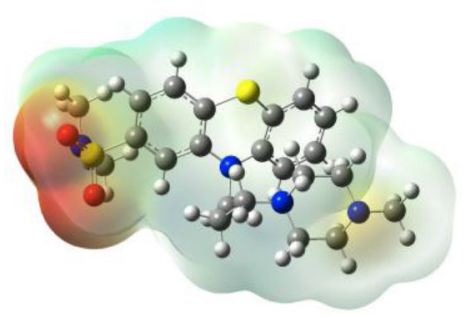

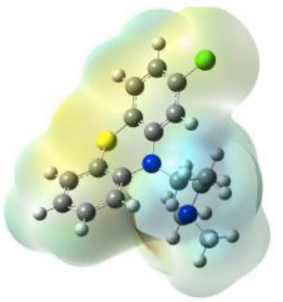

Fluphenazine

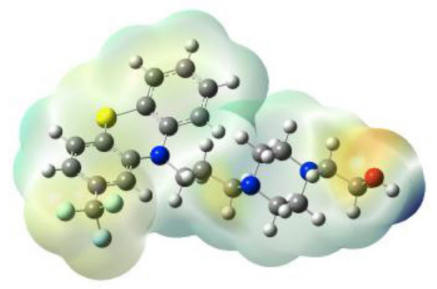

Pipotiazine

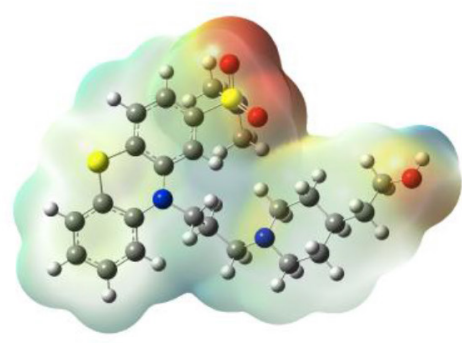

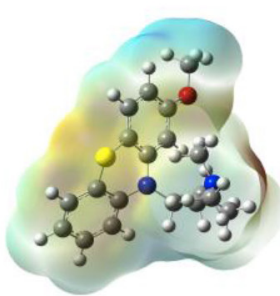

Trifluoperazine

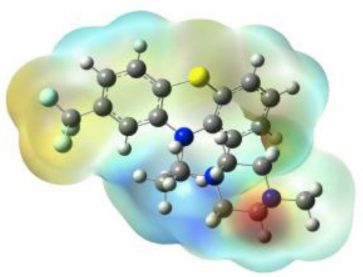

Periciazine

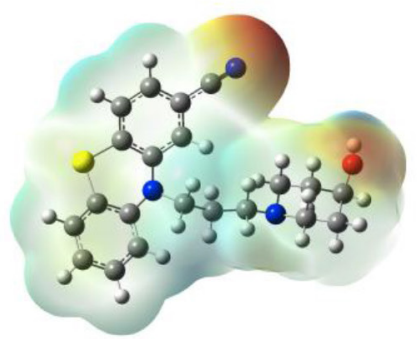

Figure 9. Molecular Electrostatic Potential (MEP) of the systems under study.

\section{Acknowledgment}

This study was funded by DGAPA-PAPIIT, Consejo Nacional de Ciencia y Tecnología (CONACyT), and resources provided by the Instituto de Investigaciones en Materiales (IIM). This work was carried out using a NES super computer, provided by Dirección General de Cómputo y Tecnologías de Información y Comunicación (DGTIC), Universidad Nacional Autónoma de México (UNAM). We would like to thank the DGTIC of UNAM for their excellent and free supercomputing. We also thank the Laboratorio de Supercómputo y Visualización en Paralelo at the Universidad Autónoma MetropolitanaIztapalapa for the access to its computer facilities. Authors would like to acknowledge Oralia L Jiménez A., María Teresa Vázquez and Caín González for their technical support.

\section{References}

1. Li P, Snyder GL, Vanover KE (2016) Dopamine Targeting Drugs for the Treatment of Schizophrenia: Past, Present and Future. Curr Top Med Chem 16: 3385-3403. [crossref]

2. Wickelgren I (1998) A new route to treating schizophrenia? Science 281: 1264 1265. [crossref]

3. Marino MJ, Knutsen LJ, Williams M (2008) Emerging opportunities for antipsychotic drug discovery in the postgenomic era. J Med Chem 51: 1077-1107. [crossref]

4. Forray C, Buller R (2017) Challenges and opportunities for the development of new antipsychotic drugs. Biochem Pharmacol 143: 10-24. [crossref]

5. Hosák L, Hosakova J (2015) The complex etiology of schizophrenia general state of the art. Neuro. Endocrinol Lett 36: 631-637. [crossref]

6. RÄfdulescu A (2009) A multi-etiology model of systemic degeneration in schizophrenia. J Theor Biol 259: 269-279. [crossref]

7. Walker E, Kestler L, Bollini A, Hochman KM (2004) Schizophrenia: etiology and course. Annu Rev Psychol 55: 401-430. [crossref]

8. Dean B (2012) Neurochemistry of schizophrenia: the contribution of neuroimaging postmortem pathology and neurochemistry in schizophrenia. Curr Top Med Chem 12: 2375-2392. [crossref] 
9. Delay J, Deniker P, Harl JM (1952) [Therapeutic method derived from hibernotherapy in excitation and agitation states]. Ann Med Psychol (Paris) 110: 267-273. [crossref]

10. Laborit H, Huguenard P, Alluaume R (1952) [A new vegetative stabilizer; 4560 R.P..]. Presse Med 60: 206-208. [crossref]

11. López-Muñoz F, Alamo C, Cuenca E, Shen WW, Clervoy P, et al. (2005) History of the discovery and clinical introduction of chlorpromazine. Ann Clin Psychiatry 17: 113-135. [crossref]

12. Ban TA (2007) Fifty years chlorpromazine: a historical perspective. Neuropsych Disease Treat 3: 495-500. [crossref]

13. Kim DH, Maneen MJ, Stahl SM (2009) Building a better antipsychotic: receptor targets for the treatment of multiple symptom dimensions of schizophrenia. Neurotherapeutics 6: 78-85. [crossref]

14. Mailman RB, Murthy V (2010) Third generation antipsychotic drugs: partial agonism or receptor functional selectivity?. Curr Pharm Des 16: 488-501. [crossref]

15. CARLSSON A, LINDQVIST M (1963) EFFECT OF CHLORPROMAZINE OR HALOPERIDOL ON FORMATION OF 3METHOXYTYRAMINE AND NORMETANEPHRINE IN MOUSE BRAIN. Acta Pharmacol Toxicol (Copenh) 20: $140-144$. [crossref]

16. Creese I, Burt DR, Snyder SH (1976) Dopamine receptor binding predicts clinical and pharmacological potencies of antischizophrenic drugs. Science 192: 481-483. [crossref]

17. Madras BK (2013) History of the discovery of the antipsychotic dopamine D2 receptor: a basis for the dopamine hypothesis of schizophrenia. $J$ Hist Neurosci 22: 62-78. [crossref]

18. Meltzer HY (2013) Update on typical and atypical antipsychotic drugs. Annu Rev Med 64: 393-406. [crossref]

19. Samara MT, Cao H, Helfer B, Davis JM, Leucht S (2014) Chlorpromazine versus every other antipsychotic for schizophrenia: a systematic review and metaanalysis challenging the dogma of equal efficacy of antipsychotic drugs. Eur Neuropsychopharmacol 24: 1046-1055. [crossref]

20. Jaszczyszyn A, GÄ...siorowski K, ÅšwiÄ...tek P, Malinka W, CieÅslik-Boczula K, et al. (2012) Chemical structure of phenothiazines and their biological activity. Pharmacol Rep 64: 16-23. [crossref]

21. Sudeshna G, Parimal K (2010) Multiple non-psychiatric effects of phenothiazines: a review. Eur J Pharmacol 648: 6-14. [crossref]

22. Fourrier A, Gasquet I, Allicar MP, Bouhassira M, Lépine JP, et al. (2000) Patterns of neuroleptic drug prescription: a national cross-sectional survey of a random sample of French psychiatrists. Br J Clin Pharmacol 49: 80-86. [crossref]

23. Molnár J, Sakagami H, Motohashi N (1993) Diverse biological activities displayed by phenothiazines, benzo[a]phenothiazines and benz[c]acridins (review). Anticancer Res 13: 1019-1025. [crossref]

24. Horn AS, Snyder SH (1971) Chlorpromazine and dopamine: conformational similarities that correlate with the antischizophrenic activity of phenothiazine drugs. Proc Natl Acad Sci U S A 68: 2325-2328. [crossref]

25. Ford JM, Prozialeck WC, Hait WN (1989) Structural features determining activity of phenothiazines and related drugs for inhibition of cell growth and reversal of multidrug resistance, Mol Pharmacol 35: 105-115. [crossref]

26. Reina M, Martínez A (2017) Silybin interacting with $\mathrm{Cu} 4, \mathrm{Ag} 4$ and $\mathrm{Au} 4$ clusters: do these constitute antioxidant materials. Comput Theor Chem 1112: 1-9.

27. Reina M, Martínez A (2017) How the presence of metal atoms and clusters can modify the properties of silybin: a computational prediction. Comput Theor Chem 1099: 174-184.

28. Pillegowda M, Periyasamy G (2018) DFT studies on interaction between bimetallic [Au2M] clusters and cellobiose, Comput Theor Chem 1129: 26-36.

29. Martínez A, Vargas R, Galano A (2018) Citric acid: a promising copper scavenger. Comput Theor Chem 1133: 47-50.

30. Frisch MJ, Trucks GW, Schlegel HB, Scuseria GE, et al. (2009) Gaussian 09, Revision A.08 Inc. Wallingford, CT.

31. Zhao Y, Truhlar DG (2008) The M06 suite of density functionals for main group thermochemistry, thermochemical kinetics, noncovalent interactions, excited states, and transition elements: two new functionals and systematic testing of four M06class functionals and 12 other functionals, Theor Chem Acc 120: 215-241.

32. Petersson GA, Bennett A, Tensfeldt TG, Al-Laham MA, William A. Shirley (1988) A complete basis set model chemistry. I. The total energies of closed-shell atoms and hydrides of the first-row atoms, J Chem Phys 89: 2193.

33. Petersson GA, Al-Laham MA (1991) A complete basis set model chemistry. II. Open-shell systems and the total energies of the first-row atoms, J Chem Phys 94: 6081.

34. McLean AD, Chandler GS (1980) Contracted Gaussian-basis sets for molecular calculations. 1. 2nd row atoms, $\mathrm{Z}=11-18 . J$ Chem Phys 72:5639.
35. Raghavachari K, Binkley JS, Seeger R, Pople JA (1980) Self-Consistent Molecular Orbital Methods. 20. Basis set for correlated wave-functions. J Chem Phys 72: 650.

36. Marenich AV, Cramer CJ, Truhlar DG (2009) Universal solvation model base on solute electron density and on a continuum model of the solvent defined by the bulk dielectric constant and atomic surface tensions. J Phys Chem. 113: 6378.

37. Kim S, Thiessen PA, Bolton EE, Chen J, Fu G, et al. (2016) PubChem Substance and Compound databases. Nucleic Acids Res 44: D1202-1213. [crossref]

38. Gázquez JL, Cedillo A, Vela A (2007) Electrodonating and electroaccepting powers. J Phys Chem A 111: 1966-1970. [crossref]

39. Gázquez JL (2008) Perspectives on the density functional theory of Chemicals reactivity. J Mex Chem Soc 52: 3.

40. Martínez A, Rodríguez-Gironés MA, Barbosa A, Costas M (2008) Donator acceptor map for carotenoids, melatonin and vitamins. J Phys Chem A 112: 9037-9042. [crossref]

41. Martínez A (2009) Donator acceptor map of psittacofulvins and anthocyanins: are they good antioxidant substances? J Phys Chem B 113: 4915-4921. [crossref]

42. Danivas V, Venkatasubramanian G (2013) Current perspectives on chlorpromazine equivalents: comparing apples and oranges! Indian J. Psych 55: 207-208.

43. Leucht S, Samara M, Heres S, Davis JM (2016) Dose Equivalents for Antipsychotic Drugs: The DDD Method. Schizophr Bull 42: 90-94. [crossref]

44. Andreasen NC, Pressler M, Nopoulos P, Miller D, Ho BC (2010) Antipsychotic dose equivalents and dose-years: a standardized method for comparing exposure to different drugs. Biol Psychiatry 67: 255-262. [crossref]

45. Baerends EJ, Gritsenko OV, van Meer R (2013) The Kohn-Sham gap, the fundamental gap and the optical gap: the physical meaning of occupied and virtual Kohn-Sham orbital energies. Phys Chem Chem Phys 15: 16408-16425. [crossref]

46. Vargas R, Garza J, Cedillo A (2005) Koopmans-like approximation in the KohnSham method and the impact of the frozen core approximation on the computation of the reactivity parameters of the density functional theory. J Phys Chem A 109: 8880-8892. [crossref]

47. Parr RG, Gázquez JL (1993) Hardness fuctional. J Phys Chem 97: 3939-3940.

\section{Citation:}

Martínez A, Vargas R (2018) A Component of the Puzzle, When Attempting to Understand Antipsychotics: A Theoretical Study of Chemical Reactivity Indexes. J Pharmacol Pharm Res Volume 1(1): 1-8. 